\section{BMJ Open} Ophthalmology

\title{
Cost comparison between botulinum neurotoxin and surgery in the treatment of infantile esotropia in a tertiary public hospital
}

\author{
Ismail Mayet, ${ }^{1}$ Shelley-Ann McGee, ${ }^{2}$ Naseer Ally (D) , ${ }^{1}$ Hassan Dawood Alli (D) , \\ Mohammed Tikly, ${ }^{3}$ Susan Eileen Williams ${ }^{1}$
}

To cite: Mayet I, McGee S-A, Ally $\mathrm{N}$, et al. Cost comparison between botulinum neurotoxin and surgery in the treatment of infantile esotropia in a tertiary public hospital. BMJ Open Ophthalmology 2021;6:e000766. doi:10.1136/ bmjophth-2021-000766

Received 19 March 2021 Accepted 3 June 2021
Check for updates

(C) Author(s) (or their employer(s)) 2021. Re-use permitted under CC BY-NC. No commercial re-use. See rights and permissions. Published by BMJ.

${ }^{1}$ Department of Neurosciences, Division of Ophthalmology, University of the Witwatersrand, Johannesburg-Braamfontein, South Africa

${ }^{2}$ South African Medical Association, Pretoria, South Africa

${ }^{3}$ Dept of Rheuamatology, University of the Witwatersrand Faculty of Health Sciences, Johannesburg, South Africa

Correspondence to Prof. Ismail Mayet; eyemay.im@ gmail.com

\section{ABSTRACT}

Objective To compare the cost implications of botulinum neurotoxin (BNT) injection to surgery in infantile esotropia (IE) in a public/government funded hospital.

Methods and analysis A simple costing comparison was undertaken for a randomised clinical trial in IE. Patients were randomised to receive either BNT or standard surgery. The participants in the BNT arm were further subdivided into subgroups based on their age in months and degree of esotropia in prism dioptres (PD) at presentation: G1 $\leq 60 \mathrm{PD} / 24$ months, $\mathrm{G} 2 \leq 24$ months/> 60 $\mathrm{PD}, \mathrm{G} 3>24$ months/ $\leq 60 \mathrm{PD}, \mathrm{G} 4>24$ months/>60 PD. The costs were calculated for each arm from primary treatment to eventual satisfactory outcome defined as orthophoria or microtropia ( $\leq 10 \mathrm{PD}$ ). A bottom-up costing analysis was done for single and multiple procedures for each arm. Comprehensive variable costs as well as fixed costs were calculated at each point of intervention and expressed in local currency ZAR (US\$1=ZAR15.00). Costing was analysed for surgery and BNT subgroups (based on clinical success)

Results There were 101 patients enrolled in the trial. 54 in the BNT arm and 47 in the surgery arm. Cost for single surgery and single BNT was ZAR 7743.04 and 1713.14, respectively. A favourable clinical outcome was achieved in $72 \%$ of surgery arm and $37 \%$ of BNT arm. The mean cost for eventual favourable outcome in BNT arm was ZAR9158.08 and in surgery arm ZAR9124.27 ( $\mathrm{p}=0.26)$. Mean cost in G1 was ZAR6328.45, in G2 ZAR7197.45, in G3 ZAR11891.93 and G4 ZAR12882.44 ( $p=0.018)$.

Conclusion BNT has a cost-benefit in IE and is a viable option in the primary treatment of IE in resource constrained regions. Clinical outcomes and economic benefit in smaller angle of esotropia and younger patients are comparable to surgery.

\section{BACKGROUND}

Strabismus or misalignment of the eyes in children is frequently seen in paediatric ophthalmology units. Uncorrected strabismus results in functional impairment with regard to development of binocular vision and possible amblyopia, as well as psychosocial problems. ${ }^{1}$ Infantile esotropia (IE) is a common type of concomitant convergent

\section{Key messages}

What is already known about this subject?

Clinically botulinum neurotoxin (BNT) is a viable option in treating selective group of infantile esotropia, younger children with esotropia of $<50$ prism dioptres (PD)

\section{What are the new findings?}

The cost-benefit of BNT is comparable to surgery even in larger angles ( $\leq 60 \mathrm{PD}$ ) due mainly to the shorter time taken in theatre.

How might these results change the focus of research or clinical practice?

In resource limiting centres, where waiting lists are long, BNT will afford many more children access to timeous correction of their esotropia and reduce the financial cost incurred by funders.

strabismus and in our region accounts for the majority of cases. ${ }^{2}$ Surgery is the standard of care in IE with a success rate of about $75 \%-80 \%$. ${ }^{3}$ Surgical correction of strabismus in adults has been shown to be highly cost effective in developed countries. ${ }^{4}$

The duration of surgery is approximately 1 hour and this is a significant consideration in resource constrained areas where theatre availability is at a premium. In South Africa and other low-income and middle-income countries, the quest for alternative and less resource intensive procedures is challenging and the need to minimise cost while maintaining quality of service is an ongoing balancing act. Waiting lists for surgical corrections are in excess of 1 year due to the large number of children, compounded by the misconception that strabismus repair is largely 'cosmetic' and relegated as a low priority procedure in multi-disciplinary hospitals.

Botulinum neurotoxin (BNT) injections have been used as an alternative treatment option, ${ }^{5-7}$ BNT injections take about $20 \%$ of 
the total time in theatre when compared with surgery and are associated with less discomfort and pain. In a metaanalysis Issaho et al reported on nine studies using BNT for IE with success rates ranging from $37 \%$ to $100 \%{ }^{8}$ It has been reported that BNT is less effective than surgery in large angle esotropia. ${ }^{7}$ In a randomised clinical trial (RCT) conducted at our institution, we showed that BNT was successful in $37 \%$ overall for the cohort but in selected patients, specifically those younger than 24 months and those with an esotropia $<50$ prism dioptres (PD), alignment was achieved in over $50 \%$ of the study cohort. $^{9}$

Economic evaluation (EE) is defined as a 'comparative analysis of alternate courses of action in terms of both their cost and consequence'. ${ }^{10}$ Cost-utility analysis is a commonly acceptable method of reporting EE and considers cost-benefit ratio using quality adjusted life years gained. Benefit or utility gain can be calculated using several methods; Time Trade Off, Standard Gamble or Vision Analogue Scale but none has been validated in children and simple cost comparison may be more appropriate. ${ }^{11}$ There is a paucity of published articles on the cost of BNT injections in treating strabismus patients and one study showed comparable cost with long term BNT use and surgery in adults. ${ }^{12}$

This paper aims to compare the cost implications of BNT and surgery, and to determine a model to predict which group of children with IE may benefit from BNT injections as first line treatment, while keeping overall costs to a minimum.

\section{METHODOLOGY}

A simple costing analysis was undertaken using the results of a prospective randomised study over a period of 3 years from 2015 to 2018 comparing efficacy of BNT injections to surgery. One aspect of the study was to compare the cost implications between the two procedures to the hospital, both in terms of direct variable and fixed costs. The hospital is a government run hospital in South Africa Gauteng Province and all surgery is funded fully by the government with no reimbursement from health insurance and no copayment collected from patients.

The detailed protocol for the study is described elsewhere $^{9}$ but briefly children between the age of 6 months and 6 years, diagnosed with large angle IE, defined as esotropia of $\geq 40$ PD were included.

Children with other forms of esotropia, those with significant patterns and children with neuro-behavioural disorders were excluded.

Children were grouped into two age categories, those $\leq 24$ months and those $>24$ months of age. Within each age category, participants were randomised by an independent study assistant and assigned to either the BNT (odd numbers) or surgery (even numbers) arms. In the surgery arm children received standard bilateral medial rectus muscle recessions for esotropia of $\leq 60 \mathrm{PD}$ and maximum recessions of $7.0 \mathrm{~mm}$ augmented with 3 units of Botox (Allergan US) in esotropia >60 PD. Unsuccessful outcomes defined as misalignment of $>10$ PD were subjected to BNT injections as a second procedure at the 3-month visit and a second surgical procedure thereafter in failed cases. In the BNT arm, patients initially received 5 units, repeated at any of the follow-up visits at 3, 6, 12 and 24-week visits, if alignment was $>10 \mathrm{PD}$. A maximum of three injections were given before surgery was offered to correct the residual esotropia. For this study 1 vial of Botox 100 units was used for eight patients. Injections were given subconjunctivally as described by Benabent $e t$ $a l^{13}$ not requiring electromyography needles. The decision of administering a maximum of three injections was arbitrary, based on other studies that reported a mean number of 1-2.2 injections given in IE. ${ }^{6} 714$

The time taken in theatre, from anaesthetic induction to transfer out of operating theatre for each procedure was recorded. The procedures were standardised for each arm with one surgeon (IM) performing all procedures. A bottom up, micro-costing ${ }^{15}$ was done for each of the two procedures for a public/government hospital.

Clinical outcome was based on achievement of orthophoria (or within 10 PD of orthophoria).

\section{Cost calculations}

Variable costs were calculated from the information received from hospital authorities. Salaries of staff were calculated based on annual salary, hourly rate earned for each category of staff (at Department of Public Service and Administration rates) and the pro rata amount based on time taken for each procedure. Staff salaries calculated were for one specialist surgeon, one specialist anaesthetist, one professional nurse, two assistant nurses and recovery professional nurse. Other staff including the pharmacist, orthoptist, porter, hospital clerks, ward nurse and cleaners who were not directly involved with operative procedure were included in fixed costs. Fixed costs also included ward admission (bedding, preparation, food) water and electricity. Fixed costs were calculated based on the daily cost per patient of a hospital admission in a tertiary hospital supplied by the finance division of the hospital. Fixed costs for this study were calculated based on total hospital time of 6 hours in the surgery arm and 2 hours in the BNT arm. Unit prices of medication and disposable used, were obtained from the hospital pharmacy and procurement office. Although it is difficult to calculate cost of theatre per minute in the hospital, this was estimated using rates used by the private sector and based on a study conducted in South Africa comparing costs in the private and public sector. ${ }^{16}$ A portion of the private sector cost was assumed to be basic costs of theatre applicable in the public sector (we assumed a third of the cost calculated in the private sector, based on discounted rates on medicines and disposable in the government/ public sector on the one hand and the need for profit and taxes paid in the private sector on the other hand). All calculations were expressed in South African Rands 
Table 1 Financial cost per procedure to hospital in Rands (US\$1=ZAR15)

\begin{tabular}{|c|c|c|c|c|c|c|}
\hline \multirow[b]{2}{*}{ Item } & \multicolumn{3}{|l|}{ Botulinum } & \multicolumn{3}{|l|}{ Surgery } \\
\hline & Unit/pt & Unit cost/pt & Total pt cost & Unit/pt & Unit cost/pt & Total pt cost \\
\hline \multicolumn{7}{|l|}{ Anaesthetic } \\
\hline Short line & 1.0 & 15.00 & 15.00 & & & \\
\hline Intravenous line & & & & 1.0 & 35.00 & 35.00 \\
\hline Ringers sol & & & & 1.0 & 8.68 & 8.68 \\
\hline Propofol (R38/50 mL) & 5.0 & 0.76 & 3.80 & 5.0 & 0.76 & 3.80 \\
\hline Sevoflurane (R792.48/250 mL) & 10.0 & 3.68 & 36.80 & 20.0 & 3.17 & 63.40 \\
\hline Laryngeal tube & & & & 1.0 & 70.00 & 70.00 \\
\hline Oral mask & 1.0 & 4.00 & 4.00 & & & \\
\hline miscellaneous & & & 15.00 & & & 15.00 \\
\hline \multicolumn{7}{|l|}{ Surgical } \\
\hline Gloves & 1.0 & 12.00 & 12.00 & 2.0 & 12.00 & 24.00 \\
\hline 4/0 silk & & & & 2.0 & 81.46 & 162.92 \\
\hline $5 / 0$ vicryl & & & & 2.0 & 119.79 & 239.58 \\
\hline $8 / 0$ vicryl & & & & 1.0 & 138.96 & 138.96 \\
\hline cautery & & & & 1.0 & 75.00 & 75.00 \\
\hline Sponges/packet & & & & 1.0 & 48.00 & 48.00 \\
\hline Botulinum R1552.00/100 units* & 10.0 & 15.52 & 155.20 & & & \\
\hline Insulin syringes & 2.0 & 1.00 & 2.00 & & & \\
\hline Balance salt solution (10 mL) & & & & 1.0 & 12.00 & 12.00 \\
\hline TTO ointment & & & & 1.0 & 48.00 & 48.00 \\
\hline Time in theatre $(\mathrm{min}) \dagger$ & 11.0 & 50.00 & 550.00 & 72.0 & 50.00 & 3600.00 \\
\hline \multicolumn{7}{|l|}{ Staff required } \\
\hline Surgeon (R462.92/hour) & 11.0 & 7.68 & 84.52 & 72.0 & 7.68 & 553.10 \\
\hline Anaesthetist (R462.92/hour) & 11.0 & 7.68 & 84.52 & 72.0 & 7.68 & 553.10 \\
\hline Professional nurse (R150/hour) & 11.0 & 2.50 & 27.50 & 72.0 & 2.50 & 180.00 \\
\hline Assistant nurse $\times 2$ (R120/hour) & $11.0 \times 2$ & 2.00 & 44.00 & $72.0 \times 2$ & 2.00 & 288.00 \\
\hline Recovery nurse (R150/hour) & 15.0 & 2.50 & 37.50 & & 2.50 & 75.00 \\
\hline Time in recovery & 10.0 & 25.00 & 250.00 & 20.0 & 25.00 & 500.00 \\
\hline Fixed costs $\dagger^{*}$ & 2 hours & 176.25 & 352.50 & 6 hours & 176.25 & 1057.50 \\
\hline Total & & & 1713.14 & & & $7743.04 \ddagger$ \\
\hline
\end{tabular}

${ }^{*}$ Cost of botulinum 100 units/8 patients.

†Cost of theatre based on gases used, microscope use, bedding @ZAR50/min (assumed 1/3 of private rates).

$\ddagger$ Cost for surgery if botulinum neurotoxin (BNT) given would be ZAR7900.24.

§Fixed cost-include water, electricity, ward stay @ ZAR4600/day, allowing for total hospital time of 2 hours for BNT and 6 hours for surgery.

(ZAR) and at the time of the study US\$1.00 was equivalent to ZAR15.00 (or ZAR20.00/£1.00 UK).

Various clinical subgroups and their costs were analysed, comparing surgery to single and multiple BNT injection procedures based on our RCT findings. Further analysis was done to assess viability for subsequent surgery in failed cases. Using a simple economic model, costs were calculated for different subgroups and predictions of the cost-benefit were then made.

For this analysis the BNT group were divided into four subgroups based on literature reports identifying age of presentation and degree of esotropia to be significant variables. ${ }^{716}$ The subgroups in months and PD were as follows: G1 children $\leq 24$ months of age and $\leq 60$ PD; G2 children $\leq 24$ months and $>60$ PD; G3 children $>24$ months and $\leq 60 \mathrm{PD}$; G4 children $>24$ months and $>60$ PD.

\section{Statistical analysis}

The total cost in each arm was expressed as means (SD). The difference in cost between the two arms was tested using the Wilcoxon rank-sum test. The cost difference between the number of procedures in the two arms was tested using the Kruskal-Wallis test 
Table 2 Summary of cumulative cost in two arms (amount in ZAR)

\begin{tabular}{|c|c|c|c|c|c|}
\hline & Surgery arm $n=47$ & & BNT arm $n=54$ & & $P$ value \\
\hline Procedures $(n)$ & Type of procedure & Cumulative cost & Type of procedure & Cumulative cost & \\
\hline 1 & $\begin{array}{l}\text { BMR if } \leq 60 \text { PD (19 pts) } \\
\text { BMR+BNT if }>60 P D(16 p t s)\end{array}$ & $\begin{array}{l}7743.04 \dagger \\
7900.24 \ddagger\end{array}$ & $\begin{array}{l}\text { BNT } 5 \text { units } \\
\text { (11 pts) }\end{array}$ & 1713.14 & $0.0001^{*}$ \\
\hline 2 & BNT 5 units (8 pts) & $\begin{array}{l}9456.18 \dagger \\
9613.38 \ddagger\end{array}$ & $\begin{array}{l}\text { BNT } 5 \text { units } \\
(5 \mathrm{pts})\end{array}$ & 3426.28 & \\
\hline 3 & LR resection (4 pts) & $\begin{array}{l}17200.22 \dagger \\
17356.42 \ddagger\end{array}$ & $\begin{array}{l}\text { BNT } 5 \text { units } \\
\text { ( } 4 \text { pts) }\end{array}$ & 5139.42 & \\
\hline 4 & - & - & BMR (34 pts) & 12882.46 & \\
\hline Mean cost & & 9124.27 & & 9158.08 & $p=0.26$ \\
\hline
\end{tabular}

*Kruskal-Wallis: †surgery only: łsurgery augmented with BNT.

BMR, bimedial rectus muscle recession; BNT, botulinum neurotoxin; LR, lateral rectus.

Parents of participants or the public did not participate in the design, or conduct, or reporting, or dissemination plans of our research.

\section{RESULTS}

Of the 101 patients analysed in this study. Fifty-four patients were enrolled in the BNT arm and 47 in the surgery arm.

Overall success rate for alignment was $37 \%$ in the BNT arm $(20.3 \%, 9.3 \%$ and $7.4 \%$ with 1,2 and 3 injections, respectively) and $70.2 \%$ after one procedure in the surgery arm. Success in the surgery arm was independent of age and degree of esotropia while in the BNT arm, success was associated with age of intervention and degree of misalignment, with age $<21$ months and degree $<50$ PD being comparable statistically, to surgery alone. Subgroup analysis of the different groups in the BNT arm showed that, G1 had an overall success of 11/16 (68.8\%), G2 5/15 (33.3\%), G3 2/10 (20\%) and G4 2/13 (15.4\%). The mean time taken was 11 min for BNT injection and 72 min for surgery.

\section{Economic findings}

Detailed costing breakdown are shown in table 1. Time in theatre cost (ZAR3600 for surgery and ZAR550 for BNT), staff cost (ZAR1649 for surgery and ZAR278.04 for BNT) and consumables (ZAR1001.76 for surgery and ZAR243.80 BNT) were the main cost determinates.

The cumulative costs for multiple procedures for both arms are shown in table 2.

The cost of a single BNT procedure was found to be ZAR1713.14 (in 11 children), the cumulative cost of BNT injection was ZAR3426.28 for two injections (in 5 children) and ZAR5139.42 for three injections (in 4 children). The cumulative cost in failed cases requiring surgery was ZAR12882.46 (in 34 children). The cost of single surgical procedure was ZAR7743.04 for esotropia $\leq 60 \mathrm{PD}$ and ZAR7900.24 in esotropia $>60$ PD due to the augmented BNT injection. Using Wilcoxon rank-sum test there was no statistical difference in the mean cost between the surgical arm and the BNT arm $(\mathrm{p}=0.26)$. The mean cost was ZAR9158.08 and ZAR9124.27 in BNT arm and in the surgery arm, respectively.

Mean cost (SD) for the subgroups in the BNT arm were 6328.45 (2655) in G1, 7197.45 (3103.73) in G2, 11891.93 (6406.28) in G3 and 12882.44 in G4. In comparing the cost between the different BNT groups there was a clear difference between groups $(p=0.018)$ although the numbers were small in each group.

\begin{tabular}{llllll}
\hline Table 3 & Model predicting total cost for eventual successful outcome for 100 cases in each group & \\
\hline & 1st & 2nd & 3rd & 4th & Total projected/100 \\
\hline Surgery & $7743.04 \times 70$ & $9456.18 \times 17$ & $17199.22 \times 13$ & 0 & 924466.47 \\
BNT G1 & $1713.14 \times 38$ & $3426.28 \times 12$ & $5139.42 \times 19$ & $12882.46 \times 31$ & 567472.25 \\
BNT G2 & $1713.14 \times 13$ & $3426.28 \times 20$ & 0 & $12882.46 \times 67$ & 949282.19 \\
BNT G3 & $1713.14 \times 20$ & 0 & 0 & $12882.46 \times 80$ & 1064859.6 \\
BNT G4 & 0 & $3426.28 \times 8$ & $5139.42 \times 8$ & $12882.46 \times 84$ & 1155711.9 \\
\hline
\end{tabular}

Cost comparison of 100 patients in each group based on actual clinical outcome of original cohort: *surgery arm: 1st procedure, surgery, 2nd procedure BNT, 3rd procedure surgery in 70,17 and 13 cases, respectively.

G1 children $\leq 24$ months of age and $\leq 60 \mathrm{PD}$; G2 children $\leq 24$ months and >60 PD; G3 children $>24$ months and $\leq 60$ PD; G4 children >24 months and $>60$ PD (cost in ZAR).

${ }^{*}$ BNT arm numbers reflect expected successful outcome with each procedure in the different groups.

BNT, botulinum neurotoxin. 
Scenario model

To better illustrate the cost between the two procedures we extrapolated success rates for the surgery and BNT subgroups from the RCT reflecting the efficacy of the two procedures for 100 patients in each group. In the surgery arm, 70 would require one procedure, 17 would require two procedures and 13 would require three procedures at total cost of ZAR924466.47 in successfully treating 100 patients. Comparatively, the total cost for BNT would be ZAR567472.25 in arm G1 and ZAR1155711.90 for the G4 subgroup for the similar 100 patient model (table 3).

\section{DISCUSSION}

Surgical correction of strabismus has been demonstrated to be cost effective in studies conducted in adults in the USA, and by extension in children. ${ }^{4}$ Other related strabismus studies have reported probable cost effectiveness in the screening for amblyopia. ${ }^{17}{ }^{18}$ While cost implications with the use of prescription glasses for various ophthalmic conditions including esotropia have also been reported. ${ }^{19}$ Such studies have been undertaken in developed countries and in general, EE analyses are sparse for low-income and middle-income countries. ${ }^{20}$ Our study was designed to establish the economic cost in the treatment of IE in an attempt to contain costs.

The study was a simple cost comparison between BNT injection and surgery which is the standard of care in IE in a government run public hospital where the majority of the population is treated. The study was necessitated by the heavy burden on theatre resources in our region with the consequence that strabismus cases especially in children are often delayed. In performing cost analyses we used activity-based costing bottom up method as this is deemed appropriate. ${ }^{21}$ The success rate of BNT has been shown to vary and in our study, surgery was two times as successful however, in our setting at least a third of children were aligned at an earlier age using BNT than if they had waited for standard surgery. Moreover, in children (G1) with angles of deviation $<60$ PD and injected at a younger age $(<24$ months $)$ the clinical success was found to be $68 \%$ and comparable to surgery but with a clear economic benefit in considering BNT as a first line intervention. Even in G2 and G3 BNT was economically viable and should still be considered as first line option. Surgery should be considered in older children with very large angles (G4).

From our findings the main cost drivers were associated with time spent in theatre, which was $6 \times$ more with surgery, resulting in greater the staff costs followed by consumables needed and anaesthesia.

\section{LIMITATIONS}

Several difficulties were associated with costing in large government hospitals such as evaluating fixed costs like electricity, water and sanitation that would apply even at times when theatres are not functional. These estimations or assumptions may skew the costs.
The multi dosing of BNT is probably only applicable in public hospitals seeing a lot of strabismus patients and scheduling regular BNT theatre lists.

With the use of BNT, repeat injections require multiple anaesthesia which theoretically increases the risk to the child although the BNT children had shorter anaesthetic time and no intubation. Longer follow-up time may be required for stable alignment and reduce the potential for fusion and depth perception. This may be undesirable in developed countries where waiting times for surgery are short. In low-income and middle-income countries these waiting times may be much longer making BNT a more viable option. The study did not address the indirect cost to the patient and society as a whole.

\section{CONCLUSION}

The knock-on effect of availing timeous intervention to many more children as well as the cumulative cost involved is a mitigating factor in considering BNT as a viable first line option. This consideration is even more compelling in the subgroup of patients $\leq 24$ months of age and $\leq 60 \mathrm{PD}$ where the clinical outcome is comparable to surgery and the economic advantage more pronounced. In children $\leq 24$ months and $>60$ PD and $>24$ months and $\leq 60$ PD BNT may economically still be an option. In children $>24$ months and $>60$ PD surgery should be considered as treatment.

Acknowledgements We wish to thank our hospital management for availing the cost processes to us.

Contributors All authors contributed equally in the research paper.

Funding The authors have not declared a specific grant for this research from any funding agency in the public, commercial or not-for-profit sectors.

Competing interests None declared.

Patient and public involvement Patients and/or the public were not involved in the design, or conduct, or reporting, or dissemination plans of this research.

Patient consent for publication Not required.

Ethics approval The study was approved by the Human Ethics Committee of the University of the Witwatersrand.

Provenance and peer review Not commissioned; externally peer reviewed.

Open access This is an open access article distributed in accordance with the Creative Commons Attribution Non Commercial (CC BY-NC 4.0) license, which permits others to distribute, remix, adapt, build upon this work non-commercially, and license their derivative works on different terms, provided the original work is properly cited, appropriate credit is given, any changes made indicated, and the use is non-commercial. See: http://creativecommons.org/licenses/by-nc/4.0/.

\section{ORCID iDs}

Naseer Ally http://orcid.org/0000-0002-6676-9352

Hassan Dawood Alli http://orcid.org/0000-0002-8687-0925

\section{REFERENCES}

1 Pathai S, Cumberland PM, Rahi JS. Prevalence of and early-life influences on childhood strabismus: findings from the millennium cohort study. Arch Pediatr Adolesc Med 2010;164:250-7.

2 Tinley C, Grötte R. Comitant horizontal strabismus in South African black and mixed race children--a clinic-based study. Ophthalmic Epidemiol 2012;19:89-94.

3 Kushner BJ, Morton GV. A randomized comparison of surgical procedures for infantile esotropia. Am J Ophthalmol 1984;98:50-61.

4 Beauchamp GR, Felius J, Stager DR, et al. The utility of strabismus in adults. Trans Am Ophthalmol Soc 2005;103:164-72. 
5 Scott $A B$. Botulinum toxin injection into extraocular muscles as an alternative to strabismus surgery. Ophthalmology 1980;87:1044-9.

6 McNeer KW, Tucker MG, Spencer RF. Botulinum toxin therapy for essential infantile esotropia in children. Arch Ophthalmol 1998;116:701-3.

7 de Alba Campomanes AG, Binenbaum G, Campomanes Eguiarte G. Comparison of botulinum toxin with surgery as primary treatment for infantile esotropia. J Aapos 2010;14:111-6.

8 Issaho DC, Carvalho FRdeS, Tabuse MKU, et al. The use of botulinum toxin to treat infantile esotropia: a systematic review with meta-analysis. Invest Ophthalmol Vis Sci 2017;58:5468-76.

9 Mayet I, Ally N, Alli HD, et al. Botulinum neurotoxin injections in essential infantile esotropia-a comparative study with surgery in large-angle deviations. Eye 2021. doi:10.1038/s41433-020-01300-4. [Epub ahead of print: 11 Jan 2021].

10 Drummond MF, Mooney GH. Essentials of health economics. Part $\mathrm{V}$--Assessing the costs and benefits of treatment alternatives. $\mathrm{Br}$ Med J 1982;285:1561-3.

11 Thorrington D, Eames K. Measuring health utilities in children and adolescents: a systematic review of the literature. PLoS One 2015;10:e0135672.

12 Gardner R, Dawson EL, Adams GG, et al. Long-term management of strabismus with multiple repeated injections of botulinum toxin. $J$ Aapos 2008;12:569-75.
13 Benabent EC, García Hermosa P, Arrazola MT, et al. Botulinum toxin injection without electromyographic assistance. J Pediatr Ophthalmol Strabismus 2002;39:231-4.

14 Scott AB, Magoon EH, McNeer KW, et al. Botulinum treatment of childhood strabismus. Ophthalmology 1990;97:1434-8.

15 Potter S, Davies C, Davies G, et al. The use of micro-costing in economic analyses of surgical interventions: a systematic review. Health Econ Rev 2020;10:3.

16 Ramjee S. Comparing the cost of delivering hospital services across the public and private sectors in South Africa. The hospital association of South Africa. University of Cape Town, 2013.

17 König H-H, Barry J-C. Cost effectiveness of treatment for amblyopia: an analysis based on a probabilistic Markov model. Br J Ophthalmol 2004;88:606-12.

18 Rein DB, Wittenborn JS, Zhang X, et al. The potential costeffectiveness of amblyopia screening programs. J Pediatr Ophthalmol Strabismus 2012;49:146-55. quiz 145, 156.

19 Malvankar-Mehta MS, Wilson R, Leci E, et al. Cost and quality of life of overlooked eye care needs of children. Risk Manag Healthc Policy 2018;11:25-33.

20 Griffiths UK, Legood R, Pitt C. Comparison of economic evaluation methods across low-income, middle-income and high-income countries: what are the differences and why? Health Econ 2016;25 Suppl 1:29-41.

21 Mercier G, Naro G. Costing Hospital surgery services: the method matters. PLoS One 2014;9:e97290. 